\title{
LAND USE CHANGES AND ITS DRIVING FACTORS: A CASE STUDY IN NANPING CITY, CHINA
}

\author{
FAN, X. C. ${ }^{1,2}-$ ZHAO, L. L. ${ }^{{ }^{*}}$ \\ ${ }^{1}$ College of Urban and Rural Construction, Shaoyang University, 422000 Shaoyang, China \\ (phone: +86-157-7406-0460) \\ ${ }^{2}$ Forestry College, Fujian Agriculture and Forestry University, 350002 Fuzhou, China \\ (phone: +86-157-2743-5965) \\ *Corresponding author \\ e-mail: lily639@163.com \\ (Received 23 ${ }^{\text {rd }}$ Dec 2018; accepted $14^{\text {th }}$ Feb 2019)
}

\begin{abstract}
Changes in land use affect the living environment of humans, considering even the survival and development of human beings. Study on the driving mechanism of land use plays a vital role in the accurate prediction of the changing trends of land use, and sustainable development of land. In this study, the Landsat images in Nanping City from 1995, 2010 and 2015 were obtained and processed using ENVI 5.2 and Arcgis 10.1. Object-oriented classification was used as the land use classification in this study. Transition matrix was used to study the characteristics, directions and structures of land use changes. The driving factors that led to the land use changes were studied using qualitative analysis and quantitative analysis (principal component analysis). The results showed that the forestland increased greatly and the cultivated land decreased significantly over the 20 years. Population, economy, urban development, policy, spending power, and technical factors were the drivers of the land use changes. The impact of comprehensive factors on the land use changes gradually increased with time.
\end{abstract}

Keywords: remote sensing, GIS, transition matrix, principal component analysis, Fujian

\section{Introduction}

Land is an indispensable resource for humans because of food supplies. Land use changes are the process that human beings constantly change land surface for surviving and developing (Aklile and Beyene, 2014; Bestelmeyer et al., 2016; Maimaitijiang et al., 2015). Human behavior changes the coverings of land surface and affects the natural ecosystems on the earth's surface, such as the cycles of energy, water, biochemistry, and atmospheric circulation (Allan et al., 1997; Liu et al., 2010). Therefore, Land Use and Land Cover Change (LUCC) proposed by the International Geosphere-Bisphere Program (IGBP) and the International Human Dimensions Program (IHDP) in the 1990s has become the frontier of global environmental change research (Turner, 1997). Land use changes are one of the three important issues of LUCC research (Alexander et al., 2015). It has a profound impact on the global sustainable development (García-Ruiz et al., 1996; Lovell, 2010; Young et al., 2005). Therefore, the studies of land use changes and its impact on the surrounding environment have become an extremely important research field in sustainable development (Renetzeder et al., 2008).

Studies of the driving mechanism of land use changes are also the core of land use changes research. The shortage of land resources and the deterioration of ecological environment caused by irrational land use are increasingly serious with the continuous development of industrialization and urbanization, and the increase of population, and the continuous expansion of human activities (Meyfroidt et al., 2013; Chaudhary et al., 2015; Song et al., 2015). Examining the driving factors have a highlighted practical 
significance in accurately predicting the trends of land use changes, the rational planning of regional land, and the protection of ecological environment (Liu et al., 2016; Zhang et al., 2015). Driving factors of land use changes can be divided into natural and socio-economic factors (Maimaitijiang et al., 2015). The impact of the natural factors, such as topographic gradient, elevation, climate, etc., on land use was not obvious during a short period of time. However, the impact of socio-economic factors covering population, economic status, policies, on land use was significant during a period of the 20 years (Girma et al., 2014). Therefore, we focused on the socioeconomic driver of the land use in this study.

The Economic Zone on the West Side of the Taiwan Straits is a regional economic complex. Its purpose is to cooperate with Taiwan in economy and is to drive the growth of economy in China. Nanping, the study area, is located in the central region of the Economic Zone. Consequently, studies of the driving factors in Nanping provided an important basis for the sustainable development, ecological protection, and the formulation of relevant policies and regulations in the Economic Zone.

\section{Materials and methods}

\section{Study area}

Nanping, the study area, is located in the southeast coast of China and the west side of the Taiwan Straits (Fig. 1). The climate belongs to the subtropical humid monsoon with an average annual temperature of $17-19^{\circ} \mathrm{C}$, an average winter temperature of 6$9^{\circ} \mathrm{C}$, an average summer temperature of $28-29{ }^{\circ} \mathrm{C}$, and an average annual rainfall of 1684-1780 mm.

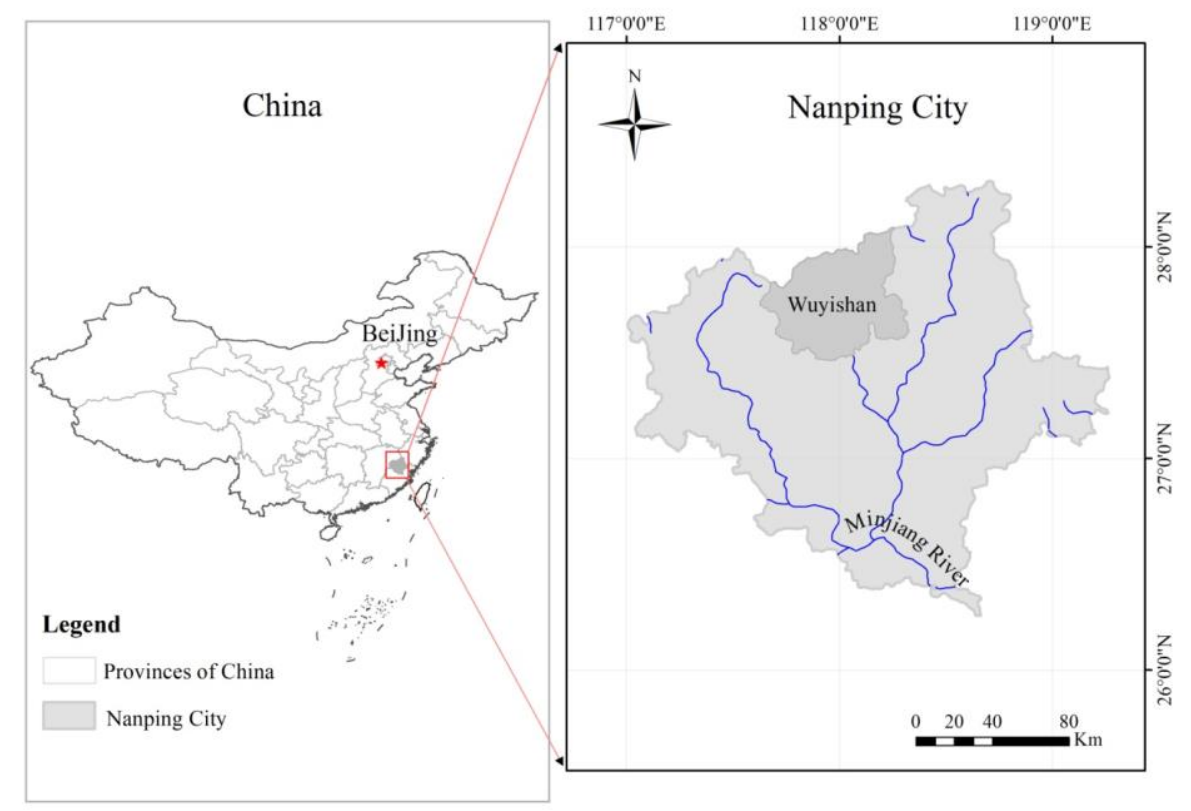

Figure 1. Map of study area

It has a history of more than 4000 years, a population of 3.19 million, and an area of $26,300 \mathrm{~km}^{2}$. The area of the bamboo forest accounts for one-tenth of that of China. In 
2015, the gross domestic product (GDP) achieved 20.933 billion USD, amd the forest coverage was $74.75 \%$. It ranks first in the reserves of niobium and tantalum in Asia. It not only is the birthplace of Minjiang River that is the mother river of Fujian Province but also is one of the best ecological regions in the world at the same latitude. Wuyishan under the jurisdiction of Nanping is one of the four World Natural and Cultural Heritage in China.

\section{Acquisition and processing of the remote sensing data}

The remote sensing images from Landsat-5 TM (1995 and 2010) and Landsat-7 ETM (2015) were derived from Chinese geospatial data cloud (http://www.gscloud.cn/). The images from Landsat-7 were processed using strip treatment. Cloud coverage of these images is less than $10 \%$. The track numbers were respectively $120 / 40,119 / 40$, $119 / 41,119 / 42,120 / 42,121 / 41,120 / 41$. Other study materials include the statistical yearbook from 1995 to 2015(NSB, 1995; NSB, 2005; NSB, 2015), the topographic maps of 1: 50000 and the administrative zoning maps obtained by Geographical information monitoring cloud platform (http://www.dsac.cn/).

These remote sensing images had undergone the correction of ground control point geometry and DEM terrain before downloaded. Therefore, the processing of remote sensing data in this study was to do color synthesis, mosaic, clip and object-oriented classification using ENVI 5.2. Types of the land use were divided into six categories: forestland, grassland, cultivated land, construction land, water and unused land. Band 5, 4 , and 3 (RGB) was used for object-oriented classification. 250 samples for each type of land use were selected to achieve better classification results. The field investigation and interactive verification using Google Earth were carried out. After field verification, the classification accuracy of the remote sensing images from the three periods was $88.30 \%, 90.70 \%$, and $92.10 \%$, respectively, which can meet the requirements of this study.

\section{Transition matrix of land use}

Transfer matrix is used commonly to study the characteristics, directions and structures of land use changes. It not only can express the structural characteristics of land use, but also indicate the source and composition of each type of land use during study period. In addition, transition matrix can also generate a transition probability matrix that can be sorted by percentage. The major and secondary land use types that causing the changes of land use can be found by the sequence and the reason of the changes can be analyzed.

The mathematical equation of transfer matrix is as follows:

$$
P_{i j}=\left[\begin{array}{cccc}
P_{11} & P_{12} & \ldots & P_{1 n} \\
P_{21} & P_{22} & \ldots & P_{2 n} \\
\vdots & \vdots & \vdots & \vdots \\
P_{n 1} & P_{n 2} & & P_{n n}
\end{array}\right]
$$

where $P$ represents the area; and $i$ and $j$ expresses the land use type at the early and late stages of study period respectively; and $n$ indicates the number of land use types. 
The transfer probability matrix in this study was calculated using post-classification images of the land use and Change Detection Statistics tool of Spatial Analysis Module from ENVI classic 5.1 according to Equation 1.

\section{Principal component analysis}

Principal component analysis is to recombine variables that have a certain correlation with each other into those with non-correlation. It extracts some new variables from original variables, and represents the information of the original variables as many as possible with minimum amount of the variables.

The mathematical model of principal component analysis is as follows:

$$
\left\{\begin{array}{c}
F_{1}=a_{11} Z X_{1}+a_{21} Z X_{2}+\cdots+a_{P 1} Z X_{P} \\
F_{2}=a_{12} Z X_{1}+a_{22} Z X_{2}+\cdots+a_{P 2} Z X_{P} \\
\vdots \\
F_{i}=a_{1 i} Z X_{1}+a_{2 i} Z X_{2}+\cdots+a_{P i} Z X_{P}
\end{array}\right.
$$

where $a_{1 i}+a_{2 i}+\cdots(i=1, \cdots, m)$ indicates the eigenvector corresponding to $X$ covariance matrix; and $Z X_{1}+Z X_{2}+\cdots$ donates the value after normalized original variable.

Principal component analysis was used to examine the impact of socio-economic driving factors on the land use changes according to Equation 2. However, the selection rules of socio-economic factors needed to be determined at first. The rules and the operation steps are as follows:

1. Review the statistical yearbook of Nanping to ensure that the factors are easy to be quantified and have a significant relationship with the land use changes.

2. Review the two statistical yearbooks of 1995 and 2015 to make sure the data of the chosen factors are complete.

3. The units of the chosen factors are different. Hence, these data need to be processed in a non-dimensional manner for subsequent calculation using SPSS.

4. Confirm the data are suitable for principal component analysis. If appropriate, correlation coefficient among the data is calculated, and Bartlett and KMO are tested. Finally, principal components are extracted using SPSS.

5. Comprehensive score of the driving factors of land use changes is obtained by multiplying the obtained eigenvectors and normalized data.

\section{Results}

\section{Areal changes of the land use}

The area of various land use types was achieved using ArcGIS 10.1 during the 20 years (Table 1). As shown in Table 1, the land use types were dominated by forestland, cultivated land and grassland, accounting for over $89 \%$ of the total area in Nanping City. The forestland increased rapidly with a total increase of $2075.90 \mathrm{~km}^{2}$. The construction land had a significant rise with an increase of $329.99 \mathrm{~km}^{2}$. In contrast, the cultivated land declined with a reduction of $1198.70 \mathrm{~km}^{2}$. The water, unused land, and grassland also decreased with a reduction of $32.65 \mathrm{~km}^{2}, 545.10 \mathrm{~km}^{2}$, and $528.03 \mathrm{~km}^{2}$ respectively. 
Table 1. Areal changes of different land use types during the 20 years $\left(\mathrm{km}^{2}\right)$

\begin{tabular}{c|c|c|c|c}
\hline Land use types & $\mathbf{1 9 9 5}$ & $\mathbf{2 0 1 0}$ & $\mathbf{2 0 1 5}$ & Changing value $\left(\mathbf{k m}^{\mathbf{2}}\right)$ \\
\hline Construction land & 771.64 & 1350.44 & 1101.63 & 329.99 \\
Forestland & 19304.79 & 19258.94 & 21380.69 & 2075.90 \\
Water area & 657.49 & 645.76 & 624.84 & -32.65 \\
Cultivated land & 2305.14 & 2452.60 & 1106.44 & -1198.70 \\
Unused land & 955.46 & 770.43 & 410.36 & -545.10 \\
Grassland & 2172.78 & 1796.45 & 1644.75 & -528.03 \\
\hline
\end{tabular}

\section{Transfer matrix of the land use}

As shown in Table 2 that the value of outflow of the forestland was the lowest with a value of $16.64 \%$. In contrast, unused land had a highest value $(99.5 \%)$ in outflow. The order of the outflow of these land use types was unused land $(99.5 \%)>$ cultivated land $(91.86 \%)>$ water $(84.14 \%)>$ construction land $(77.64 \%)>$ grassland $(76.91 \%)>$ forestland (16.64\%). The main transition directions of all the land use types were forestland, which caused the continuous increase in forestland over the 20 years. In addition, grassland was also one of the transition directions of the unused land. The construction land and grassland were the main outflow types of cultivated land.

Table 2. Transfer matrix of land use in the study area from 1995 to 2015 (\%)

\begin{tabular}{c|c|c|c|c|c|c}
\hline 2015 1995 & $\begin{array}{c}\text { Construction } \\
\text { land }\end{array}$ & Forestland & Water & Cultivated land & Unused land & Grassland \\
\hline Construction land & 22.36 & 6.05 & 10.83 & 20.60 & 11.04 & 7.08 \\
Forestland & 57.68 & 83.36 & 64.96 & 47.55 & 53.74 & 65.35 \\
Water & 11.60 & 2.55 & 15.86 & 3.10 & 1.85 & 1.52 \\
Cultivated land & 3.36 & 1.15 & 1.95 & 8.14 & 4.43 & 2.68 \\
Unused land & 0.20 & 0.10 & 0.16 & 0.53 & 0.50 & 0.28 \\
Grassland & 4.80 & 6.79 & 6.24 & 20.08 & 28.44 & 23.09 \\
\hline
\end{tabular}

\section{Driving factors of the land use}

\section{Comprehensive driving factors of the society and economy}

From Table 3, 12 factors were selected in this study. Owing to the greater number of these factors, they were reduced dimensionally in order that most information was expressed with the least number of the factors. The correlation coefficient matrixes were obtained using these dimensionless factors (Table 4). As shown in Table 4, the correlation coefficients were all higher except GDP and natural population growth rate, which indicated the greater repetitiveness of information expressed by these factors. Accordingly, principal component analysis, and Bartlett and KMO tests were implemented. The value (Sig.) of Bartlett's concomitant probability was 0.000 , less than the significance level (0.05), and the KMO value was 0.865 , which showed these factors were linearly correlated and principal component analysis were adopted compatibly.

As shown in Table 5, one principal component was achieved according to the principle of specifying eigenvalue $>1$ and initial eigenvalue $>80 \%$. The initial eigenvalue of the first principal component was $83.75 \%$, which indicated that it 
reflected $83.75 \%$ of the overall factors. Hence, it could explain the reason of the land use changes.

Table 3. List of socio-economic factors

\begin{tabular}{c|c|c|c}
\hline Code & Name & Unit & Types of factor \\
\hline X1 & Total population & Person & Demographic factors \\
\hline X2 & GDP & Billion USD & \\
X3 & Primary industry & Billion USD & \\
X4 & Secondary industry & Billion USD & \multirow{2}{*}{ Economic factors } \\
X5 & Tertiary industry & Billion USD & \\
X6 & Local fiscal revenue & Billion USD & \\
X7 & Local financial expenditure & Billion USD & \\
\hline X8 & The total retail sales of social consumer goods & Billion USD & \multirow{2}{*}{ Spending power } \\
X9 & Resident deposits end of the year & Billion USD & \\
\hline X10 & Natural population growth rate & $\%$ & Social awareness factors \\
\hline X11 & The total social investment in fixed assets & Billion USD & Technical factors \\
\hline X12 & Per capita net income of farmers & USD & Spending power \\
\hline
\end{tabular}

Table 4. Correlation coefficient matrix among these driving factors

\begin{tabular}{c|c|c|c|c|c|c|c|c|c|c|c|c}
\hline Factors & $\mathbf{Z X}_{\mathbf{1}}$ & $\mathbf{Z X}_{\mathbf{2}}$ & $\mathbf{Z X}_{\mathbf{3}}$ & $\mathbf{Z X}_{\mathbf{4}}$ & $\mathbf{Z X}_{\mathbf{5}}$ & $\mathbf{Z X}_{\mathbf{6}}$ & $\mathbf{Z X}_{\mathbf{7}}$ & $\mathbf{Z X}_{\mathbf{8}}$ & $\mathbf{Z X}_{\mathbf{9}}$ & $\mathbf{Z X}_{\mathbf{1 0}}$ & $\mathbf{Z X}_{\mathbf{1 1}}$ & $\mathbf{Z X}_{\mathbf{1 2}}$ \\
\hline $\mathbf{Z X}_{\mathbf{1}}$ & 1.000 & & & & & & & & & & & \\
$\mathbf{Z X}_{\mathbf{2}}$ & -.184 & 1.000 & & & & & & & & & & \\
$\mathbf{Z X}_{\mathbf{3}}$ & -.168 & .998 & 1.000 & & & & & & & & & \\
$\mathbf{Z X}_{\mathbf{4}}$ & -.177 & .999 & .998 & 1.000 & & & & & & & & \\
$\mathbf{Z X}_{\mathbf{5}}$ & -.203 & .997 & .992 & .994 & 1.000 & & & & & & & \\
$\mathbf{Z X}_{\mathbf{6}}$ & -.154 & .992 & .991 & .994 & .984 & 1.000 & & & & & & \\
$\mathbf{Z X}_{\mathbf{7}}$ & -.155 & .984 & .981 & .986 & .977 & .995 & 1.000 & & & & & \\
$\mathbf{Z X}_{\mathbf{8}}$ & -.192 & .999 & .995 & .997 & .997 & .993 & .988 & 1.000 & & & & \\
$\mathbf{Z X}_{\mathbf{9}}$ & -.202 & .996 & .991 & .994 & .997 & .988 & .984 & .999 & 1.000 & & & \\
$\mathbf{Z X}_{\mathbf{1 0}}$ & -.033 & .280 & .257 & .296 & .270 & .331 & .324 & .292 & .287 & 1.000 & & \\
$\mathbf{Z X}_{\mathbf{1 1}}$ & -.156 & .978 & .973 & .980 & .974 & .991 & .996 & .984 & .982 & .365 & 1.000 & \\
$\mathbf{Z X}_{\mathbf{1 2}}$ & -.185 & .998 & .994 & .996 & .998 & .991 & .984 & .999 & .998 & .288 & .982 & 1.000 \\
\hline
\end{tabular}

Table 5. Eigenvalue and cumulative rate of driving factors

\begin{tabular}{c|c|c|c|c|c|c}
\hline \multirow{2}{*}{$\begin{array}{c}\text { Principal } \\
\text { component }\end{array}$} & \multicolumn{3}{|c|}{ Initial eigenvalue } & \multicolumn{3}{c}{ Rotation square sum loading } \\
\cline { 2 - 7 } & Total & $\begin{array}{c}\text { Variance } \\
(\boldsymbol{\%})\end{array}$ & $\begin{array}{c}\text { Accumulative } \\
\text { total (\%) }\end{array}$ & Total & $\begin{array}{c}\text { Variance } \\
(\boldsymbol{\%})\end{array}$ & $\begin{array}{c}\text { Accumulative } \\
\text { total (\%) }\end{array}$ \\
\hline 1 & 10.05 & 83.75 & 83.75 & 10.05 & 83.75 & 83.75 \\
\hline
\end{tabular}

As shown in Table 6, the loads values of the factors exceed 0.9 except for the total population and the natural population growth rate. From Table 6, the values exceed 0.9 that represented economic factors, spending power and technical factors. Consequently, 
the three types of the factors were the dominating ones for the land use changes in Nanping during the study period.

Table 6. List of factors loading matrix

\begin{tabular}{c|c|c}
\hline Index of factors & Factors & Component 1 \\
\hline$Z_{1}$ & Total population &. .197 \\
$Z_{1} X_{2}$ & .997 \\
$Z_{3}$ & GDP & .993 \\
$Z_{4}$ & Primary industry & .997 \\
$Z_{4}$ & Secondary industry & .994 \\
$Z_{5}$ & Tertiary industry & .996 \\
$Z_{6}$ & Local fiscal revenue & .991 \\
$Z_{7}$ & Local financial expenditure & .999 \\
$Z_{8}$ & The total retail sales of social consumer goods & .997 \\
$Z_{9}$ & Resident deposits end of the year & .329 \\
$Z_{10}$ & Natural population growth rate & .989 \\
$Z_{11}$ & The total social investment in fixed assets & .997 \\
\hline
\end{tabular}

A principal component expression was obtained using the principal component load matrix and the result of the eigenvectors multiplying with the normalized data.

$$
\begin{aligned}
& F=-0.0621 Z X_{1}+0.3145 Z X_{2}+0.3132 Z X_{3}+0.3145 Z X_{4} \\
& +0.3136 Z X_{5}+0.3142 Z X_{6}+0.3126 Z X_{7}+0.3151 Z X_{8}+ \\
& 0.3145 Z X_{9}+0.1038 Z X_{10}+0.3120 Z X_{11}+0.3145 Z X_{12}
\end{aligned}
$$

The comprehensive score of the factors of the land use changes was calculated using Equation 3. As can be seen from Figure 2, the impact of the factors on the land use changes showed a sharp increase over time. Specifically, the comprehensive score of the factors had increased slowly before 2008, which indicated that economic factors, spending power and technical factors had little effect on the land use changes. However, the score of driving factors had demonstrated an exponential growth after 2008. This was mainly due to the rapid increase in GDP, the continuous development of high-tech industries, the integration of geographical advantages and the adjustment of industrial layout in Nanping after 2008.

\section{Discussion}

\section{Population}

Population is one of the most active drivers of land use changes (Shoshany and Goldshleger, 2002). The increase of population directly changes spatial distribution of land use. According to the statistical yearbook of Nanping City from 1995 and 2015, it was found that the population in Nanping City was continuously increasing from 2,939,904 in 1995 to 3,198,600 in 2015 with an increase of 258,700 over the 20 years. This phenomenon was bound to cause changes in the land use (Bilsborrow et al., 1992; Miao et al., 2016; Rufino et al., 2017). The large-scale facilities, such as water, 
electricity, early warning facilities, and the daily facilities, such as landfill, recreational facilities, water supply system, resident health information system and school informatization, and other convenient service facilities were constructed during this time in order to deal with the increase of population (Liu et al., 2006; Sun et al., 2013). The construction of these facilities profoundly affected the spatial distribution of the land use in Nanping.

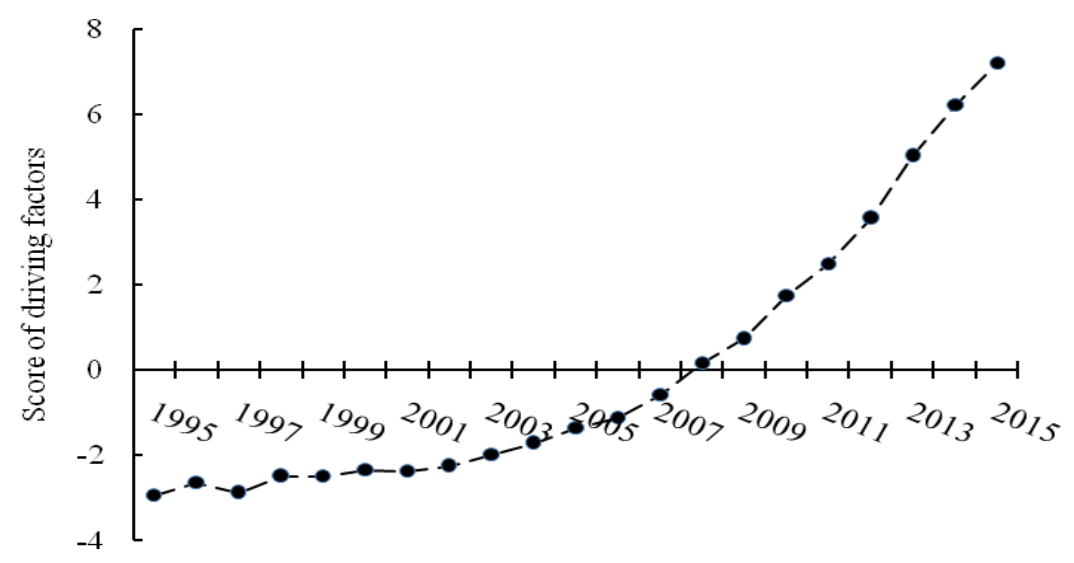

Figure 2. Comprehensive score of socio-economic driving factor of the land use change

The growth in the population led to a marked increase in the construction land and a significant decrease in the cultivated land over the 20 years. The construction land and cultivated land increased and decreased by $329.99 \mathrm{~km}^{2}$ and $1198.7 \mathrm{~km}^{2}$ respectively. It was found that the construction land was one of the main transfer directions of the cultivated land, which indicated that population growth inevitably increased the construction of large-scale convenient services facilities, resulting in more the cultivated land being transferred to the construction land. However, cultivated land is the main source of food for human beings. The rapid population growth led to the conversion of more cultivated land into the construction land, which inevitably led to insufficient food supply. Therefore, it is crucial to solve the contradiction between population and cultivated land. In summarize, population was one of the main factors causing the changes in the land use.

\section{Economy}

GDP refers to the status of regional economy. The growth of GDP represents the improvement of people's living level, which is the prevalent aspiration and struggle target of people. The activities of human beings for living affect changes in land use types. Hence, economic development inevitably leads to changes in land use (Weber et al., 2001). GDP in Nanping was continuously increasing from 2.28 billion USD in 1995 to 20.94 billion USD in 2015 (Fig. 3). The citizens began to seek spiritual enjoyment after satisfying their food and clothing needs. For raising the living quality and meeting spiritual needs of the citizens, the municipal government accelerated the construction of infrastructure buildings, which led to the significant changes of the land use in Nanping (Liu et al., 2015). 
According to the Classification of Chinese Economic Industries, agriculture, forestry, animal husbandry, and fishery were classified as the primary industry, and the supply and construction industries such as mining, manufacturing, electricity, and gas were classified as secondary industry, and service industry as the tertiary industry.

As shown in Figure 3, the rankings of the three industries in Nanping City significantly changed during the 20 years. The proportion of the primary industry decreased from $34.44 \%$ in 1995 to $21.59 \%$ in 2015, the secondary industry increased from $35.82 \%$ in 1995 to $43.16 \%$ in 2015 and the tertiary industry only increased by $5.52 \%$ over the 20 years, which showed that the agriculture, forestry, animal husbandry and fishery gradually turned to service industry and manufacturing industry.

In this study, the decrease in the proportion of the primary industry (agriculture, forestry, animal husbandry and fishery) indicated the decline in the cultivated land and grassland. With the increase in the proportion of the secondary and tertiary industry, more land resources were occupied by the facilities, which means that the increase in the construction land and the decrease in the unused land. In summarize, the changes of the economy undoubtedly affect the spatial distribution of the land use (Fan et al., 2017). Economy is one of the driving factors of the land use changes in Nanping.

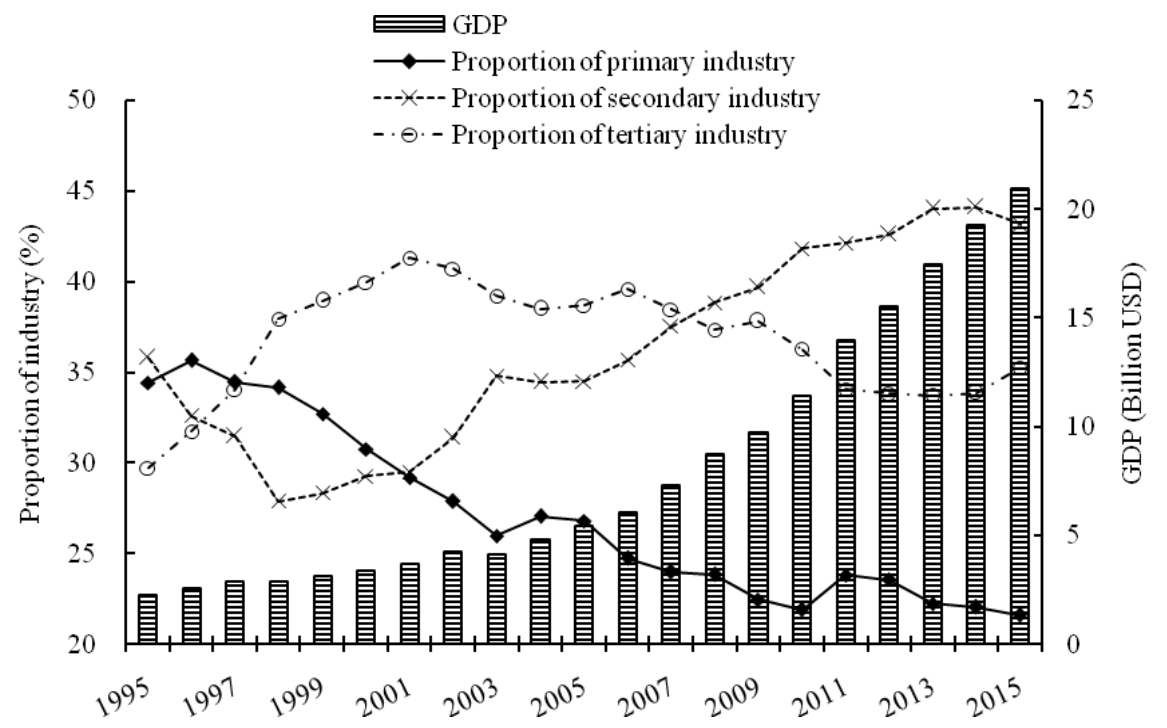

Figure 3. The proportion of GDP and three major industries in the study area

\section{Urbanization and transportation}

Urbanization is a symbol of the improvement of people's living level (Sigel, 1978). It is a kind of development trends to shift from simple agricultural life to multiple city life for human beings. However, a series of environments problems, such as biodiversity loss, heat island effect, environmental pollution, and water and soil loss, have arisen due to the rapid urbanization and irrational use of land resources (Wang et al., 2012). The urban construction in Nanping continued to expand outward over the 20 years. The urbanization rate in Nanping increased from $29.0 \%$ in 1995 to $54.0 \%$ in 2015 with an increase of 27.0\% (NSB, 1995; NSB, 2015), which led to the changes of the land use.

Accordingly, the staggered road networks resulted in the serious destruction of the landscape (Mo et al., 2017). In 2015, the total mileage of the roads was $15554.24 \mathrm{~km}$ 
and mileage of freeway was $929.67 \mathrm{~km}$, and the pavement with asphalt and cement concrete were $877.48 \mathrm{~km}$ and 10846.19, respectively (NSB, 2015). The intensity of the fragmentation in the landscape was obviously enhanced, which led to the decrease in the types of the landscape such as cultivated land, water and grassland (Jaeger et al., 2007). In short, the development of the urbanization and transportation led to the dramatic changes of the land use.

\section{Policy}

The main pillars of the development plan of the Economic Zone issued by the state council were as follows.

1. Strengthen exchanges and cooperation between mainland China and Taiwan by virtue of the construction of Pingtan Experimental Zone which is a nearest island in mainland China to Taiwan.

2. Accelerate infrastructure construction and improve sustainability in economic development in the Economic Zone.

3. Accelerate optimization in industrial layout and improve innovation capability in order to build a modern industrial system of the Economic Zone.

4. Realize the coordinated development of the urban and rural areas.

5. Focus on improving people's livelihood and build a harmonious atmosphere in the Economic Zone.

6. Improve ecological environment of the Economic Zone and strive to build a sustainable development area with beautiful living environment.

According to these pillars, it is necessary to construct the economic zone into a beautiful, ecological, and friendly region, and focus on the coordinated development of the economy and the ecological environment. It is therefore indispensable to increase the forestland so as to maintain the stability of the ecosystem and improve the ecological environment (Wang et al., 2017). In this study, the forestland had decreased by $45.85 \mathrm{~km}^{2}$ from 1995 to 2010 before the "Plan" was promulgated. However, from 2010 to 2015 , the forestland had increased by $2121.75 \mathrm{~km}^{2}$ after the "Plan" was issued, which further illustrated the decisive role of policies in the land use changes.

The Development Plan for Wuyishan was promulgated in 2010, which is of great significance to further improve the economy in Nanping. Accordingly, new land policies were introduced by the government. The forestry reform was executed and inappropriate cultivated land was retreated. As a result, the forestland continued to increase after 2010. Especially, the cultivated land had increased before 2010. In contrast, it had decreased sharply after 2010. Consequently, the promulgation and implementation of the policies had a profound impact on the spatial distribution of the land use (Dempsey et al., 2017).

\section{Conclusion}

The main conclusions are as follows:

The percentage of forestland in overall study region increased significantly from $73.77 \%$ in 1995 to $81.39 \%$ in 2015 with an increase of $2075.90 \mathrm{~km}^{2}$ over the 20 years. The cultivated land decreased sharply from $8.81 \%$ in 1995 to $4.21 \%$ in 2015 with a decline of $1198.70 \mathrm{~km}^{2}$. 
The unused land, cultivated land, and water had a higher outflow over the 20 years. The forestland was the main outflow types for the land use types. Hence, the forest coverage rate remarkably increased.

The study found that the growth of population and economy, and urban expansion resulted in the sharp increase of construction land, and the decline of cultivated land, grassland and unused land. National and local policies led to a notable increase in the forestland and the decline in the cultivated land over the study period. In a word, the comprehensive impact of population, economy, urban development and policies was the main reason for the land use changes in Nanping during the study period.

Economic factors, spending power and technical factors were the driving factors of the land use changes. The impact of the three drivers on land use changes demonstrated an exponential rise after the year of 2008.

In summary, population, economy, urban development, policy, spending power, and technical factors were the driving factors of the land use changes in Nanping over the 20 years.

Acknowledgements. The authors are so grateful to Specialized Research Fund for the Doctoral Program of Shaoyang University (Fund No. 17ZX03), and National Science and Technology Major Project of the Ministry of Science and Technology of China (Fund No. 2017YFD0601304) for financial support.

\section{REFERENCES}

[1] Aklile, Y., Beyene, F. (2014): Examining drivers of land use change among pastoralists in Eastern Ethiopia. - Journal of Land Use Science 9(4): 402-413.

[2] Allan, D., Erickson, D., Fay, J. (1997): The influence of catchment land use on stream integrity across multiple spatial scales. - Freshwater Biology 37(1): 149-161.

[3] Alexander, P., Rounsevell, M. D. A., Dislich, C., Dodson, J. R., Engström, K., Moran, D. (2015): Drivers for global agricultural land use change: the nexus of diet, population, yield and bioenergy. - Global Environmental Change 35: 138-147.

[4] Bestelmeyer, B. T., Okin, G. S., Duniway, M. C., Archer, S. R., Sayre, N. F., Williamson, J. C., Herrick, J. E. (2016): Desertification, land use, and the transformation of global drylands. - Frontiers in Ecology and the Environment 13(1): 28-36.

[5] Bilsborrow, R. E., Okoth-Ogendo, H. W. O. (1992): Population-driven changes in land use in developing countries. - Ambio 21(1): 37-45.

[6] Chaudhary, A., Verones, F., Baan, L. D., Hellweg, S. (2015): Quantifying land use impacts on biodiversity: combining species-area models and vulnerability indicators. Environmental Science and Technology 49(16): 9987-9995.

[7] Dempsey, J. A., Plantinga, A. J., Kline, J. D., Lawler, J. J., Martinuzzi, S., Radeloff, V. C., Bigelow, D. P. (2017): Effects of local land-use planning on development and disturbance in riparian areas. - Land Use Policy 60: 16-25.

[8] Fan, M., Shibata, H., Chen, L. (2017): Environmental and economic risks assessment under climate changes for three land uses scenarios analysis across Teshio watershed, northernmost of Japan. - Science of the Total Environment 599-600: 451-463.

[9] García-Ruiz, J. M., Lasanta, T., Ruiz-Flano, P., Ortigosa, L., White, S., González, C., Martí, C. (1996): Land-use changes and sustainable development in mountain areas: a case study in the Spanish Pyrenees. - Landscape Ecology 11(5): 267-277.

[10] Girma, H. M., Hassan, R. M. (2014): Drivers of land-use change in the Southern nations, nationalities and people's region of Ethiopia. - African Journal of Agricultural and Resource Economics 09: 148-164. 
[11] Jaeger, J. A. G., Schwarz von Raumer, H. G., Esswein, H., Müller, M., Schmidtlüttmann, M. (2007): Time series of landscape fragmentation caused by transportation infrastructure and urban development: a case study from Baden-Württemberg, Germany. - Ecology and Society 12(1): 181-194.

[12] Liu, J., Zhang, Z., Xu, X., Kuang, W., Zhou, W., Zhang, S., Li, R., Yan, C., Yu, D., Wu, S. (2010): Spatial patterns and driving forces of land use change in China during the early 21 st century. - Journal of Geographical Sciences 20(4): 483-494.

[13] Lovell, S. T. (2010): Multifunctional urban agriculture for sustainable land use planning in the United States. - Sustainability 2(8): 2499-2522.

[14] Liu, F., Yan, H., Liu, J., Xiao, X., Qin, Y. (2016): Spatial pattern of land use intensity in China in 2000. - Acta Geographica Sinica 71(7): 1130-1143.

[15] Liu, S., Wei, S., Gao, Y., Yan, X. (2015): Study on the coordinative development between urban land intensive utilization and urbanization based on coupling model: a case study of 9 cities divided into districts in Fujian Province. - Journal of Fujian Normal University (Natural Science Edition) 31(2): 96-105.

[16] Liu, Y., Chen, Y. (2006): Impact of population growth and land-use change on water resources and ecosystems of the arid Tarim River Basin in Western China. - International Journal of Sustainable Development \& World Ecology 13(4): 295-305.

[17] Maimaitijiang, M., Ghulam, A., Sandoval, J. S. O., Maimaitiyiming, M. (2015): Drivers of land cover and land use changes in St. Louis metropolitan area over the past 40 years characterized by remote sensing and census population data. - International Journal of Applied Earth Observations and Geoinformation 35(3): 161-174.

[18] Meyfroidt, P., Lambin, E. F., Erb, K. H., Hertel, T. W. (2013): Globalization of land use: distant drivers of land change and geographic displacement of land use. - Current Opinion in Environmental Sustainability 5(5): 438-444.

[19] Miao, L., Feng, Z., Sun, Z., Moore, J. C., Cui, X. (2016): China's land-use changes during the past 300 years: a historical perspective. - International Journal of Environmental Research and Public Health 13(9): 847-863.

[20] Mo, W., Wang, Y., Zhang, Y., Zhuang, D. (2017): Impacts of road network expansion on landscape ecological risk in a megacity, China: a case study of Beijing. - Science of The Total Environment 574: 1000-1011.

[21] Nanping Statistics Bureau (NSB) (1995): Nanping Statistical Yearbook. - Chengxida Colour Printing Limited Company, Fuzhou.

[22] Nanping Statistics Bureau (NSB) (2005): Nanping Statistical Yearbook. - Chengxida Colour Printing Limited Company, Fuzhou.

[23] Nanping Statistics Bureau (NSB) (2015): Nanping Statistical Yearbook. - Chengxida Colour Printing Limited Company, Fuzhou.

[24] Renetzeder, C., Eupen, Mucher, C. A., Wrbka, T. (2008): Sustainability impact assessment of land use changes. - Sustainability Impact Assessment of Land Use Changes 33(4): 159-180.

[25] Rufino, I. A. A., Silva, S. T. D., Rufino, I. A. A., Silva, S. T. D. (2017): Change analysis of population dynamics and climate variability in the Brazilian semi-arid region: a methodological approach. - Boletim De Ciencias Geodesicas 23(1): 166-181.

[26] Song, W., Deng, X., Yuan, Y., Wang, Z., Li, Z. (2015): Impacts of land-use change on valued ecosystem service in rapidly urbanized North China Plain. - Ecological Modelling 318(318): 245-253.

[27] Shoshany, M., Goldshleger, N. (2002): Land-use and population density changes in Israel-1950 to 1990: analysis of regional and local trends. - Land Use Policy 19(2): 123-133.

[28] Sigel, L. T. (1978): Urbanization, modernization, and identity in Asia: a historical perspective. - Modern China 4(4): 461-490.

[29] Sun, Y., Susanna, T., Fang, M., Jeffrey Yang, Y. (2013): Exploring the effects of population growth on future land use change in the Las Vegas Wash watershed: an 
integrated approach of geospatial modeling and analytics. - Environment, Development and Sustainability 15(6): 1495-1515.

[30] Turner, B. L. (1997): The sustainability principle in global agendas: Implications for understanding land-use/cover change. - Geographical Journal 163(2): 133-140.

[31] Wang, J., Wang, W., Qi, Y., He, T., Wu, R., Chen, Y. (2017): Classification system and spatio-temporal distribution of ecological land in China in the period of 1996-2012. Geographical Research 36(3): 453-470.

[32] Wang, Q., Yuan, X., Ma, C., Zhang, Z., Zuo, J. (2012): Research on the impact assessment of urbanization on air environment with urban environmental entropy model: a case study. - Stochastic Environmental Research and Risk Assessment 26(3): 443-450.

[33] Weber, A., Fohrer, N., Möller, D. (2001): Long-term land use changes in a mesoscale watershed due to socio-economic factors - effects on landscape structures and functions. - Ecological Modelling 140(1-2): 125-140.

[34] Young, J., Watt, A., Nowicki, P., Alard, D., Clitherow, J., Henle, K., Johnson, R., Laczko, E., Mccracken, D., Matouch, S. (2005): Towards sustainable land use: identifying and managing the conflicts between human activities and biodiversity conservation in Europe. - Biodiversity and Conservation 14(7): 1641-1661.

[35] Zhang, Y., Guo, S., Liu, Q., Jiang, J., Wang, R., Li, N. (2015): Responses of soil respiration to land use conversions in degraded ecosystem of the semi-arid Loess Plateau. - Ecological Engineering 74: 196-205. 